OPEN ACCESS

Edited by:

Rui Rosa,

University of Lisbon, Portugal

Reviewed by:

Luis Vargas-Chacoff,

Austral University of Chile, Chile

Kim Dawn Thompson,

Moredun Research Institute, United Kingdom

*Correspondence:

F. E. Reyes-López

felipe.reyes@uab.cat

L. Tort

Lluis.Tort@uab.es

†These authors have contributed equally to this work

Specialty section:

This article was submitted to

Aquatic Physiology,

a section of the journal

Frontiers in Physiology

Received: 18 February 2019 Accepted: 23 May 2019

Published: 18 June 2019

Citation:

Liu XH, Khansari AR, Teles M, Martínez-Rodríguez G, Zhang YG, Mancera JM, Reyes-López FE and

Tort L (2019) Brain and Pituitary Response to Vaccination in Gilthead

Seabream (Sparus aurata L.).

Front. Physiol. 10:717.

doi: 10.3389/fphys.2019.00717

\section{Brain and Pituitary Response to Vaccination in Gilthead Seabream (Sparus aurata L.)}

\author{
X. H. Liu'1,2t, A. R. Khansari't, M. Teles' ${ }^{1}$, G. Martínez-Rodríguez ${ }^{3}$, Y. G. Zhang ${ }^{2}$, \\ J. M. Mancera ${ }^{4}$, F. E. Reyes-López ${ }^{1 *}$ and L. Tort ${ }^{1 *}$
}

\begin{abstract}
${ }^{1}$ Department of Cell Biology, Physiology and Immunology, Universitat Autonoma de Barcelona, Barcelona, Spain, ${ }^{2}$ Key Laboratory of Freshwater Fish Reproduction and Development (Ministry of Education), Key Laboratory of Aquatic Science of Chongqing, School of Life Sciences, Southwest University, Chongqing, China, ${ }^{3}$ Instituto de Ciencias Marinas de Andalucia, Cádiz, Spain, ${ }^{4}$ Department of Biology, Faculty of Marine and Environmental Sciences, Instituto Universitario de Investigación Marina (INMAR), Campus de Excelencia Internacional del Mar (CEl-MAR), University of Cádiz, Cádiz, Spain
\end{abstract}

Vaccination is a widely used therapeutical strategy in aquaculture, but whether vaccination elicits stress responses in the central neuroendocrine system and enhances the crosstalk between the immune and endocrine systems in the brain or pituitary after vaccination is unclear. To answer this question two experiments using two different vaccine exposure routes, i.e., bath or intraperitoneal (i.p.) injection, were carried out on gilthead seabream (Sparus aurata L.). In the first one, the stress responses of fish subjected to waterborne Vibrio anguillarum bacterin were compared with responses after air exposure or their combination. In the second experiment, fish were subjected to an intraperitoneal injection of Lactococcus garvieae bacterin and we assessed the central stress response and also whether or not a significant immune response was induced in brain and pituitary. In both experiments, blood, brain and pituitary tissues were collected at 1, 6, and $24 \mathrm{~h}$ post stress for plasma hormone determination and gene expression analysis, respectively. Results indicated that bath vaccination induced a decreased central stress response compared to air exposure which stimulated both brain and pituitary stress genes. In the second experiment, injection vaccination kept unchanged plasma stress hormones except cortisol that raised at 6 and 24 h. In agreement, non-significant or slight changes on the transcription of stress-related genes were recorded, including the hormone genes of the hypothalamic pituitary interrenal (HPI) axis and other stress markers such as hsp70, hsp90, and $m t$ genes in either brain or pituitary. Significant changes were observed, however, in crhbp and gr. In this second experiment the immune genes $i / 1 \beta$, cox 2 , and lys, showed a strong expression in both brain and pituitary after vaccination, notably il1 $\beta$ which showed more than 10 fold raise. Overall, vaccination procedures, although showing a cortisol response, did not induce other major stress response in brain or pituitary, regardless the administration route. Other than main changes, the alteration of crhbp and gr suggests that these genes could play a relevant role in the feedback regulation of HPI axis after vaccination. In addition, from the results obtained in this work, it is also demonstrated that the immune system maintains a high activity in both brain and pituitary after vaccine injection.

\footnotetext{
Keywords: brain, pituitary, vaccination, immune response, stress response
} 


\section{INTRODUCTION}

Stress is defined as a state of real or perceived challenge for homeostasis that induces a response consisting in an array of biological reactions to compensate for the consequences of the threat created by the stressor (Tort and Teles, 2011; Schreck and Tort, 2016). After the stressor is perceived, the neuroendocrine cells of the ventral parvocellular section of the nucleus preopticus, secrete different neuroendocrine players: Corticotropin Releasing Hormone (CRH), CRH Binding Peptide (CRHBP), Arginin Vasotoccin (AVT) and Thyroid Releasing Hormone (TRH) that control the production of adrenocorticotropic hormone (ACTH) in corticotropic cells of the anterior pituitary gland (Flik et al., 2006). The release of ACTH into the bloodstream and interaction with the receptors of interrenal tissue, will subsequently induce cortisol release (Gorissen and Flik, 2016). Cortisol acts as a multifunctional hormone via binding to its receptors, the mineralocorticoid receptor (MR) and glucocorticoid receptors (GR), which are ubiquitously expressed in almost all tissues (Sapolsky et al., 2000; Teles et al., 2013). During the stress response, cortisol will redirect energy utilization among various organs in order to overcome the increased metabolic demand imposed by the stressor challenge. As a consequence, some processes such as immune response mechanisms may be affected or delayed (Kaattari and Tripp, 1987; Padgett and Glaser, 2003; Kudielka and Kirschbaum, 2007). For instance, hypothalamic $\mathrm{CRH}$ may act as an anti-inflammatory via stimulation of glucocorticoids and catecholamines; peripheral $\mathrm{CRH}$ acts as pro-inflammatory through direct action on immune cells (Karalis et al., 1997; Quintanar and GuzmanSoto, 2013) and cortisol acts generally as immunosuppressor or immunomodulator (Tort, 2011). Besides, ACTH has been reported to present immunoreactive activity in the thymus of goldfish (Carassius auratus) (Ottaviani et al., 1995). In addition, the expression of some immune genes in the central nervous system has been reported, and this suggests a potential cross-interaction between brain immune and neuroendocrine systems (Metz et al., 2006). Assuming that brain and pituitary are the hierarchical onset organs of the stress reaction (Cerdá-Reverter and Canosa, 2009), other central interactions have been shown to occur at brain and pituitary level, particularly the cortisol feed-back interaction via GR (Gorissen and Flik, 2016).

Vaccination is the most effective method used nowadays in aquaculture to prevent diseases caused by pathogens (Plant and LaPatra, 2011). Available data indicates that $2 \mathrm{~h}$ after Vibrio anguillarum bacterin exposure, the expression of both pro- and anti-inflammatory genes increase in gilthead seabream (Sparus aurata) head kidney primary cell culture (Khansari et al., 2017). Moreover, vaccination by immersion leads to alteration of some immune genes including complement $c 3$, tumor necrosis factor alpha $(\operatorname{tnf} \alpha)$, lysozyme (lys) or transforming-growth factor beta (tgf $\beta$ ) in seabream mucosal tissues such as skin and gut (Khansari et al., 2018). Therefore, these previous results demonstrate that a non-specific immune response is elicited in immune tissues of fish shortly after vaccination. Also, serum or tissue antibodies such as immunoglobulin $\mathrm{M}$ and immunoglobulin $\mathrm{T}$ will increase at long-term after vaccination (Lamers et al., 1985; Mutoloki et al., 2015), together with some specific immune responses, thus contributing to the increased survival rate when fish are challenged a second time with a pathogen (Rodgers, 1990; Figueras et al., 1998). Similarly, the phagocytic activity of head kidney leucocytes isolated from turbot (Scophthalmus maximus L.) enhanced at 7 days post vaccination, and such increase lasted as long as 42 days (Figueras et al., 1998).

There are several vaccine delivery methods, including oral, immersion and injection, of which injection often shows better protection (Plant and LaPatra, 2011). However, the injection procedure can produce adverse reactions due to stress (Hastein et al., 2005), and this unavoidable stress is associated with short-term increase of plasma cortisol (Funk et al., 2004; Skinner et al., 2010). Work on stress or immune effects of vaccine delivered by intraperitoneal injection has been previously reported and shown to be dose and temperature dependent (Martínez et al., 2018; Oyarzún et al., 2019). Nevertheless, few data is available regarding the effects of vaccine on the Hypothalamus-Pituitary-Interrenal (HPI) axis at the brain and pituitary level. In a previous study of our research group, it has been shown that bacterin could elicit immune responses in cultured pituitary cells of rainbow trout (Oncorhynchus mykiss) (Liu et al., 2019), and so did when adding medium from cultured spleen cells to pituitary tissue preparations (Liu et al., 2019).

Taking all the above into consideration, the goal of the present study was to investigate the effect of vaccine in both brain and pituitary through different vaccination routes. We hypothesized that: (1) bath vaccination might evoke a significant stress response of the central neuroendocrine organs of fish; and (2) the bacterin vaccines can induce both a stress and immune response in brain and pituitary. To test these hypotheses, two experiments were performed: In the first experiment, S. aurata individuals were vaccinated by bath vaccine, subjected to air exposure stress or subjected to both (vaccine and air exposure). Plasma cortisol content as well as gene transcripts relevant to stress responses, specifically, crh, crhbp, pomca, pomcb, gr, trh, gh, prl, sl1, and sl2 were tested in the pituitary and/or brain at 1,6 , and $24 \mathrm{~h}$ post treatments. In the second experiment, we tested whether a vaccine administered through intraperitoneal injection was able to elicit a central stress response. It was also evaluated whether brain and pituitary showed a significant immune response. As fish were taken out of the water for the injection, the responses to vaccination were tested against the air-exposed mock group, thus allowing consistent comparisons with the air exposure group from the first experiment. The air exposure stressor was selected for two reasons. One, because this is a previously used and validated type of stressor related to hypoxia or anoxia experiments (Skrzynska et al., 2018). Second, because we wanted to differentiate the response of the vaccine itself compared to the response induced by a non-biotic physical stressor. 


\section{MATERIALS AND METHODS}

\section{Fish Husbandry and Experimental Design}

Two batches of gilthead seabream (110.8 $\pm 13.4 \mathrm{~g}$ and $285.6 \pm 30.2 \mathrm{~g}$ ) were transported in March and September 2017, respectively, from Aquacultura Els Alfacs (Tarragona, north-east Spain). Fish were stocked in the indoor water circular tanks (2000 L) 20 days at the Universitat Autonoma de Barcelona fish facility (AQUAB), under a 12L: 12D photoperiod, $21.4 \pm 0.6^{\circ} \mathrm{C}$ temperature, and they were fed with a commercial diet (Skretting) once per day at a maintenance ration (1.5\% body weight). During this period, no clinical signals of disease, malformation or injuries were observed, nor altered behavior. Water parameters including $\mathrm{pH}, \mathrm{NO}_{2}, \mathrm{NO}_{3}, \mathrm{NH}_{4} / \mathrm{NH}_{3}$, temperature, and salinity were monitored every day. All experimental procedures were submitted by the Ethical Committee of the Universitat Autonoma de Barcelona (CEEAH), in accordance with the international European Guiding Principles for Biomedical Research Involving Animals (EU2010/63) and authorized by the regional authority (Generalitat de Catalunya Procedure Ref. 10208).

\section{Vaccines and Sample Collection Experiment 1}

Seabream were vaccinated with ICTHIOVAC ${ }^{R}$ VR by immersion according to guidelines recommended by the company (HIPRA). ICTHIOVAC ${ }^{R}$ VR (HIPRA) is an inactivated commercial vaccine which is suitable for immersion delivery. The composition consists of inactivated $V$. anguillarum, serotype $\mathrm{O} 1, \mathrm{O} 2 \alpha$, and $\mathrm{O} 2 \beta$ with relative percent survival RPS $\geq 60 \%$, presenting all pathogenic serotypes of the bacterium, including the serogroup $\mathrm{O} 2 \alpha$ that is the most pathogenic serogroup of the bacterium (Frans et al., 2011). The second stressor, air exposure, consisted in 3 min out of the water. To this end, four groups of fish ( $n=18$ fish per group) were used for the experiment: (i) control group, fish treated with water free-vaccine in bucket, (ii) group treated with the vaccine, (iii) group subjected to air exposure during $3 \mathrm{~min}$, and (iv) group exposed to both air exposure and vaccine. There were two replicate tanks in each group. It is worth to mention that vaccination was performed $24 \mathrm{~h}$ before air-exposure stress since the preliminary result in systemic immune organs did not show any significant alteration by vaccine at early time of vaccination (data not shown). Fish were sampled after 1, 6 and 24 h. Fish were anesthetized by an overdose of tricaine methanosulphonate (MS222) and the blood from each fish was quickly collected from the caudal vein by using a heparinized $2 \mathrm{~mL}$ syringe. After fast blood collection, the pituitary gland and brain of each fish were excised, immediately frozen in liquid nitrogen and stored under $-80^{\circ} \mathrm{C}$ until use.

\section{Experiment 2}

Before the start of the experiment, a total of 36 fish were randomly divided into 2 groups (with two replicate tanks per group) as for mock injection and vaccination, and these fish were acclimatized for another 5 days in $200 \mathrm{~L}$ water circular tanks. During this period, water parameters and rearing conditions were kept the same as mentioned above. After $24 \mathrm{~h}$ fasting, all fish were slightly anesthetized by MS222 (0,1 g/L) Sigma-Aldrich, United States), and then they were quickly intraperitoneally injected with $1 \mathrm{~mL}$ sterilized PBS or $1 \mathrm{~mL}$ ICHTHIO-LG for the mock injection or vaccination groups, respectively. After the injection, fish were immediately returned to the corresponding experimental tanks. The whole operation lasted less than $3 \mathrm{~min}$. Fish from both mock injection and vaccination groups were sampled at 1,6 , and $24 \mathrm{~h}$ post injection, and blood, pituitary and brain of 6 fish from each group at each sampling time point were collected. In brief, fish was anesthetized by an overdose of MS222, the blood of each fish was quickly collected from the caudal vein by using a $5 \mathrm{~mL}$ syringe, which was pre-rinsed with lithium heparin (Deltalab, Spain), and then transferred to a clean tube with one drop of lithium heparin. After fast blood collection, the pituitary gland and brain of each fish were excised, immediately frozen in liquid nitrogen and stored under $-80^{\circ} \mathrm{C}$ until use. ICTHIO-LG Lactococosis (HIPRA, Spain) is a vaccine obtained from inactivated Lactococcus garvieae, a pathogenic agent for both cultured freshwater and marine fish at water temperature above $15^{\circ} \mathrm{C}$. The composition consists of inactivated L. garvieae with RPS $>75 \%$.

\section{Plasma Isolation and Test of Biochemical Parameters}

Plasma was separated by blood centrifugation at $1500 \times g$ for $10 \mathrm{~min}$ at $4^{\circ} \mathrm{C}$. Then the isolated plasma of each fish was transferred to a clean tube and stored at $-20^{\circ} \mathrm{C}$ until biochemical analyses. Plasma CRH and ACTH concentration were detected by using Fish CRH ELISA Kit (Cat: CK-E93386F, Yuan Ye Biotechnology, Shanghai, China) and Fish ACTH ELISA Kit (Cat: CK-E 93337F, Yuan Ye Biotechnology, Shanghai, China) according to manufacturer instructions, respectively. These Elisa kits used in the present study showed sensitivities of about $1.0 \mathrm{pg} / \mathrm{mL}$. The intraassay coefficients of variation were $<15 \%$ for both two kits. Seabream plasma cortisol levels were measured by radioimmunoassay (RIA) as described by Rotllant et al., 2006 (antibody from MO bio-medical LLC, United States, final dilution 1:4500, lower detection limit of the cortisol assay: $0.16 \mathrm{ng} / \mathrm{mL}, 100 \%$ antibody cross-reactivity with cortisol).

\section{Total RNA Extraction and Reverse Transcription Quantitative Real-Time PCR (RT-qPCR)}

Total RNA of each tissue was extracted according to the manufacturer's instructions with TRI reagent (Sigma-Aldrich, United States). The RNA concentration of RNA (260 nm) and the purity ratio (A260/A280) was measured with NanoDrop 2000 Spectrophotometer (Thermo Fisher Scientific Inc., United States). First-strand cDNA of each sample was synthesized from $1 \mu \mathrm{g}$ total RNA by using High-Capacity cDNA Reverse Transcription Kit (Applied Biosystems, United States) according to the user's manual.

RT-qPCR was performed using iTaq $^{\text {TM }}$ Universal $\mathrm{SYBR}^{\circledR}$ Green Supermix (Bio-Rad, United States) in a CFX Touch $^{\text {TM }}$ Real-Time PCR Detection System (Bio-Rad, United States). In brief, a volume of $10 \mu \mathrm{L}$ containing $0.4 \mu \mathrm{M}$ of each upstream and downstream primer (Table 1), $2 \mu \mathrm{L}$ of cDNA 
TABLE 1 | Primer information used in the present study.

\begin{tabular}{|c|c|c|c|c|}
\hline genes & Primer sequence $\left(5^{\prime}-3^{\prime}\right)$ & Accession number & Product size (bp) & Efficiency \\
\hline$\| 1 \beta$ & F: TCAGCACCGCAGAAGAAAAC R: TAACACTCTCCACCCTCCAC & AJ277166.2 & 115 & 1.97 \\
\hline $\operatorname{cox} 2$ & F: GAGTACTGGAAGCCGAGCAC R: GATATCACTGCCGCCTGAGT & AM296029.1 & 192 & 1.89 \\
\hline $\operatorname{tnf} \alpha$ & F: TCGTTCAGAGTCTCCTGCAG R:AAGAATTCTTAAAGTGCAAACACACCAAA & AJ413189.2 & 320 & 2.24 \\
\hline c3 & F: GTTCCACAACAACCCACAGC R:ACATACGCCATCCCATCCAC & HM543456.1 & 183 & 1.91 \\
\hline lys & F: TCATCGCTGCCATCATCTCC R:TGTTCCTCACTGTCCCATGC & AM749959.1 & 154 & 2.08 \\
\hline $\operatorname{tgf} \beta 1$ & F: AGACCCTTCAGAACTGGCTC R:ACTGCTITGTCTCCCCTACC & AF424703.1 & 145 & 1.9 \\
\hline$i / 10$ & F: GATCTGCTGGATGGACTGC R: GAGCGTGGAGGAATCTाTAA & JX976621.1 & 154 & 2.02 \\
\hline il6 & F: ATCCCCTCACTTCCAGCAGA R: GCTCTTCGGCTCCTCTITCT & EU244588.1 & 129 & 2.04 \\
\hline hsp70 & F: AGGTTGGGTCTGAAAGGAAC R: TGAACTCTGCGATGAAGTGG & EU805481.1 & 174 & 1.96 \\
\hline hsp90 & F: GTGGATTCTGAGGACCTGCC R: GAGAGTCTTCGTGGATGCCC & DQ524994.1 & 196 & 1.96 \\
\hline$m t$ & F: CTCTAAGACTGGAACCTG R: GGGCAGCATGAGCAGGAG & U93206.1 & 93 & 2.07 \\
\hline crh & F: ATGGAGAGGGGAAGGAGGT R: ATCTाTGGCGGACTGGAAA & KC195964.1 & 176 & 1.86 \\
\hline trh & F: GAAACGCTाTGGGATAACTCC R: CGGCGTGACTCTTGПTATGTा & KC196277.1 & 131 & 2.24 \\
\hline$g h$ & F: CGTCTCTTCTCAGCCGAT R: GCTGGTCCTCCGTCTGC & U01301.1 & 131 & 1.79 \\
\hline prl & F: TGACATCGGCGAGGACAACATT R: CGGCAGCGGAGGACTICAG & AJ509807.1 & 111 & 1.84 \\
\hline crhbp & F: GCAGCTTCTCCATCATCTACC R: ACGTGTCGATACCGCTTCC & KC195965.1 & 147 & 1.95 \\
\hline pomca & F: AGCCAGAAGAGAGAGCAGTGAT R: ATCGGGTCAGAAAACACTCA & HM584909.1 & 120 & 1.92 \\
\hline pomcb & F: AGCTCGCCAGTGAGCTGT R: CCTCCTGCATCACTTCCTG & HM584910.1 & 81 & 2.07 \\
\hline$g r$ & F: TGCTGGCGGAGATCATCACCA R:GCAGGCCAAGCGAAGGCTTA & DQ486890.1 & 182 & 2.01 \\
\hline $18 \mathrm{~s}$ & F: ACCAGACAAATCGCTCCACC R: AGGAATTGACGGGAAGGGCAC & AY587263.1 & 172 & 2.02 \\
\hline \multirow[t]{2}{*}{ rp/27 } & F: AAGAGGAACACAACTCACTGCCCCAC & AY188520.1 & 160 & 2.01 \\
\hline & R: GCTTGCCTTGCCCAGAACTTGTAG & & & \\
\hline
\end{tabular}

product, $2.6 \mu \mathrm{l}$ of MQ water, and $5 \mu \mathrm{L}$ of $2 \times$ iTaq Universal SYBR green Supermix were used for the RT-qPCR reaction. The cycling condition consisted of an initial denaturation cycle for $5 \mathrm{~min}$ at $95^{\circ} \mathrm{C}, 40 \mathrm{cycles}$ of $15 \mathrm{~s}$ at $95^{\circ} \mathrm{C}, 30 \mathrm{~s}$ at $60^{\circ} \mathrm{C}$. A melting curve analysis was carried out after the completion of RT-qPCR to verify no non-specific amplification. The reference genes $18 \mathrm{~S}$ and RPL27 were used for normalization. The quantification was performed according to Pfaffl method (Pfaffl, 2001) and corrected for the efficiency of each primer set. Value for each experimental condition was expressed as normalized relative expression, calculated in relation to the values of control group and normalized against those of the reference gene $18 \mathrm{~S}$. The amplification efficiency and product size are listed in Table 1. Six biological replicates with two technical replicates were performed for the qPCR analysis.

\section{Statistics}

For the first experiment the statistical package for social science (SPSS, v20) software was used for the analysis. The Generalized Linear Model (GzLM) was utilized considering the stressors and time dynamics as a two between-subjects factor. This model is a more flexible statistical tool than the standard general linear model (GLM) in terms of types of distribution and different covariance structure of the repeated measures does not require homogeneity of variance and it admits missing values. After the main analysis, appropriate pairwise comparisons were carried out. In the second experiment, we used either one-way ANOVA followed by Fisher's LSD post-hot test, or unpaired student's $t$-test if the equal variances were not assumed. Differences among groups were considered significant when $P<0.05$. All results were expressed as mean \pm SEM.

\section{RESULTS}

\section{Brain and Pituitary Stress Response to Bath Vaccine}

Figure 1 shows the levels of plasma cortisol after both stressors and its combination at the respective time points. Cortisol did

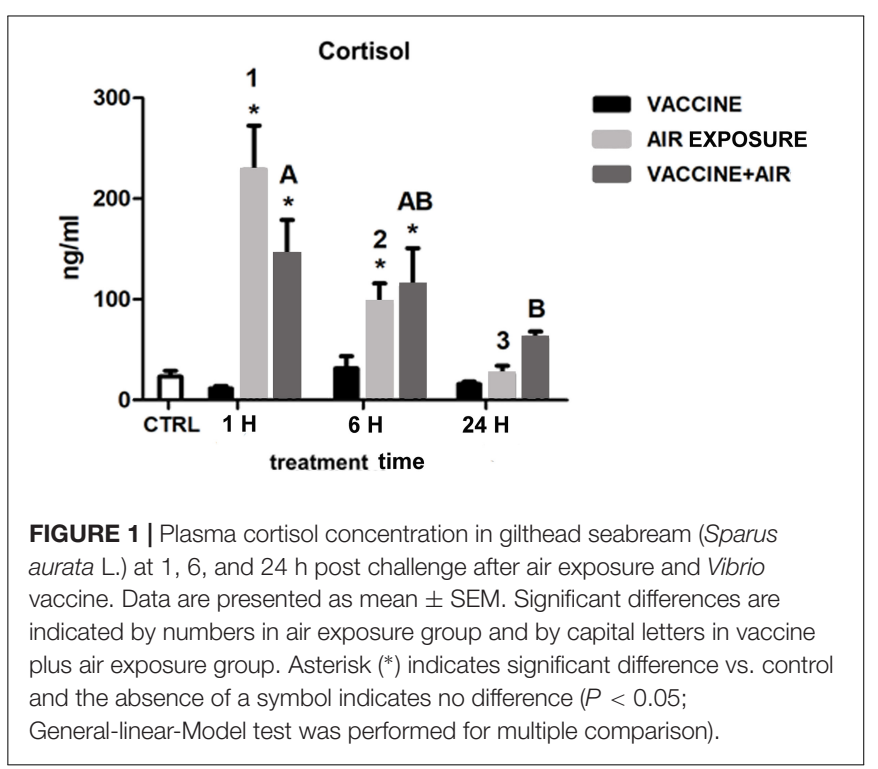


not show any significant response after bath vaccine treatment compared to air exposure stress, which showed a classical acute response dynamics with a peak at $1 \mathrm{~h}$, still significantly higher at $6 \mathrm{~h}$, followed by further recovery of basal values at $24 \mathrm{~h}$. The dynamics of the vaccine plus air exposure was similar to that observed after air exposure, although the recovery took place later on, indicating that the air exposure stressor was predominant in the cortisol response.

Regarding the response of the analyzed stress-related genes in the brain, no relevant changes were observed after bath vaccine treatment, except for a decrease of $c r h b p$ at $1 \mathrm{~h}$, whereas air exposure showed significant increases in $c r h$, crhbp, and $g r$ and a significant down-regulation of trh. When both stressors were applied, trh was maintained down-regulated at $6 \mathrm{~h}$ and only $c r h b p$ increased significantly (Figure 2).

In the pituitary, bath vaccination showed a differential induction of pomc genes at short time $(1 \mathrm{~h})$ whereas at $6 \mathrm{~h} \mathrm{prl}$ and $g h$ showed significant increases. Air exposure increased the expression of pomcb, $g r$ and sl 1 at $1 \mathrm{~h}$, and $g r$ at $6 \mathrm{~h}$. After applying both stressors only slight changes were detected as for the reductions of pomcb at $6 \mathrm{~h}$ and $s l 1$ at $1 \mathrm{~h}$, and the increase of sl1 at $6 \mathrm{~h}$ (Figure 3 ).

\section{Brain and Pituitary Stress and Immune Responses to Injected Vaccine}

Plasma cortisol values significantly raised by 2.2 - and 6.4fold compared to the corresponding mock groups at 6 and $24 \mathrm{~h}$ post injection, respectively $(P<0.05)$. The differential cortisol increase of the vaccine-injected fish compared to the mock-injected fish was apparent at all time points. Regarding time course, both injected vaccine and mock groups presented the same cortisol dynamics, i.e., increases at 1 and $6 \mathrm{~h}$ and recovery at $24 \mathrm{~h}$. However, the vaccinated group showed higher levels at either time compared to mock-injected group. The vaccine injected group also showed higher resistance to recovery at $24 \mathrm{~h}$. Regarding $\mathrm{CRH}$ or $\mathrm{ACTH}$, no alteration of plasma content in either group (mock or vaccination) was observed in none of different time points assessed 1, 6, and $24 \mathrm{~h}$ post injection (Figure 4).

In the second experiment, the expression of $c r h$ was almost unchanged at 1,6 , and $24 \mathrm{~h}$ post vaccination. Transcript of $g r$ was not altered at 1 or $24 \mathrm{~h}$, while there was a slight but significant upregulation at $6 \mathrm{~h}$ post vaccination in the mock group. A similar trend can be observed in the heat shock proteins (HSP) hsp70 and $h s p 90$ in which a significant increase was also observed at the same time point $(6 \mathrm{~h})$. As a whole, few changes were observed in brain genes, and the changes were higher in mock-injected fish than in vaccine-injected fish (Figure 5).

Similar than with the bath vaccine, the expression of stress genes in the pituitary showed a different pattern in which one gene, CRH binding protein $(c r h b p)$, substantially increased its expression (up to 15 fold at $6 \mathrm{~h}$ or up to 7 fold after $24 \mathrm{~h}$ ) after vaccine injection. These increases contrast with the mock injected
A

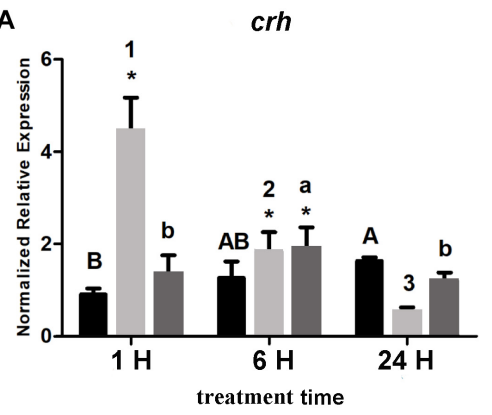

C

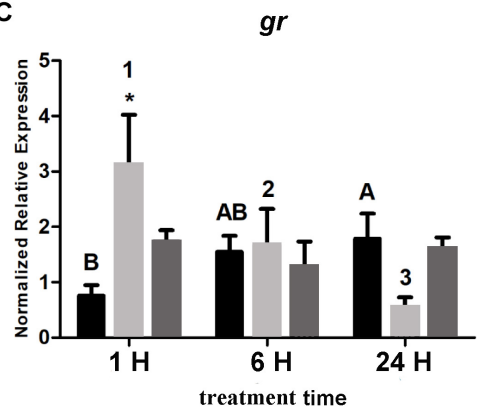

B

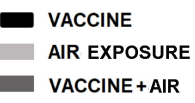

VACCINE AIR EXPOSURE VACCINE+AIR

D
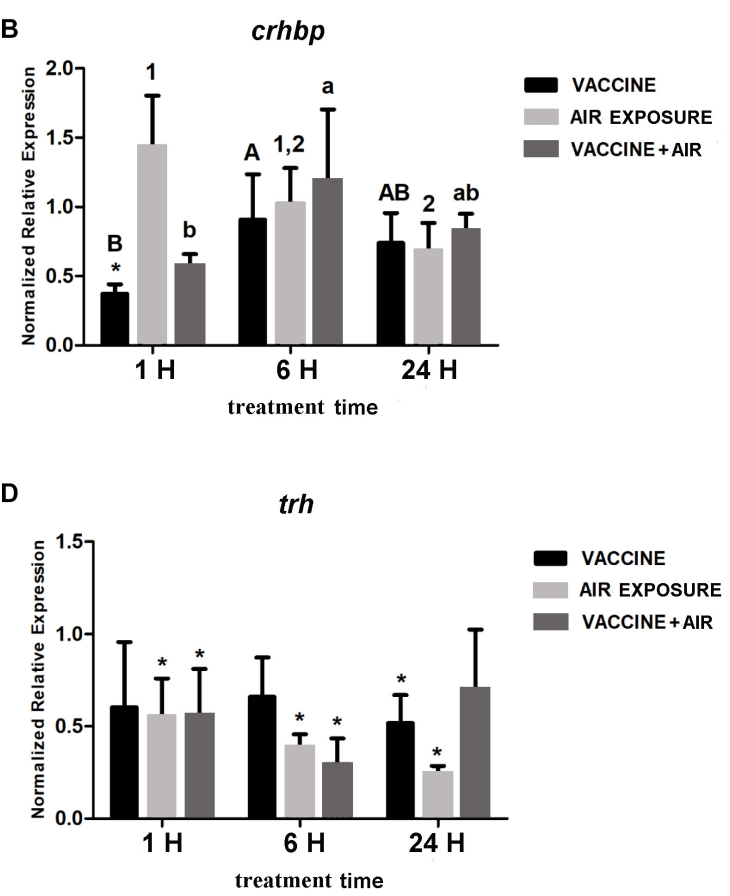

FIGURE 2 | qPCR quantification of specific mRNA accumulation in gilthead seabream (Sparus aurata L.) brain at 1, 6, and $24 \mathrm{~h}$ post challenge with Vibrio anguillarum exposure and air exposure. (A) crh; (B) crhbp; (C) gr; and (D) trh were shown as mRNA relative abundance. Data are presented as mean \pm SEM. Significant differences are indicated by capital letters in vaccine group, by numbers in air exposure group, and by lowercase letters vaccine plus air exposure. Asterisk $(*)$ indicates significant difference versus control and the absence of a symbol indicates no difference $(P<0.05$; General-linear-Model test was performed for multiple comparison). 

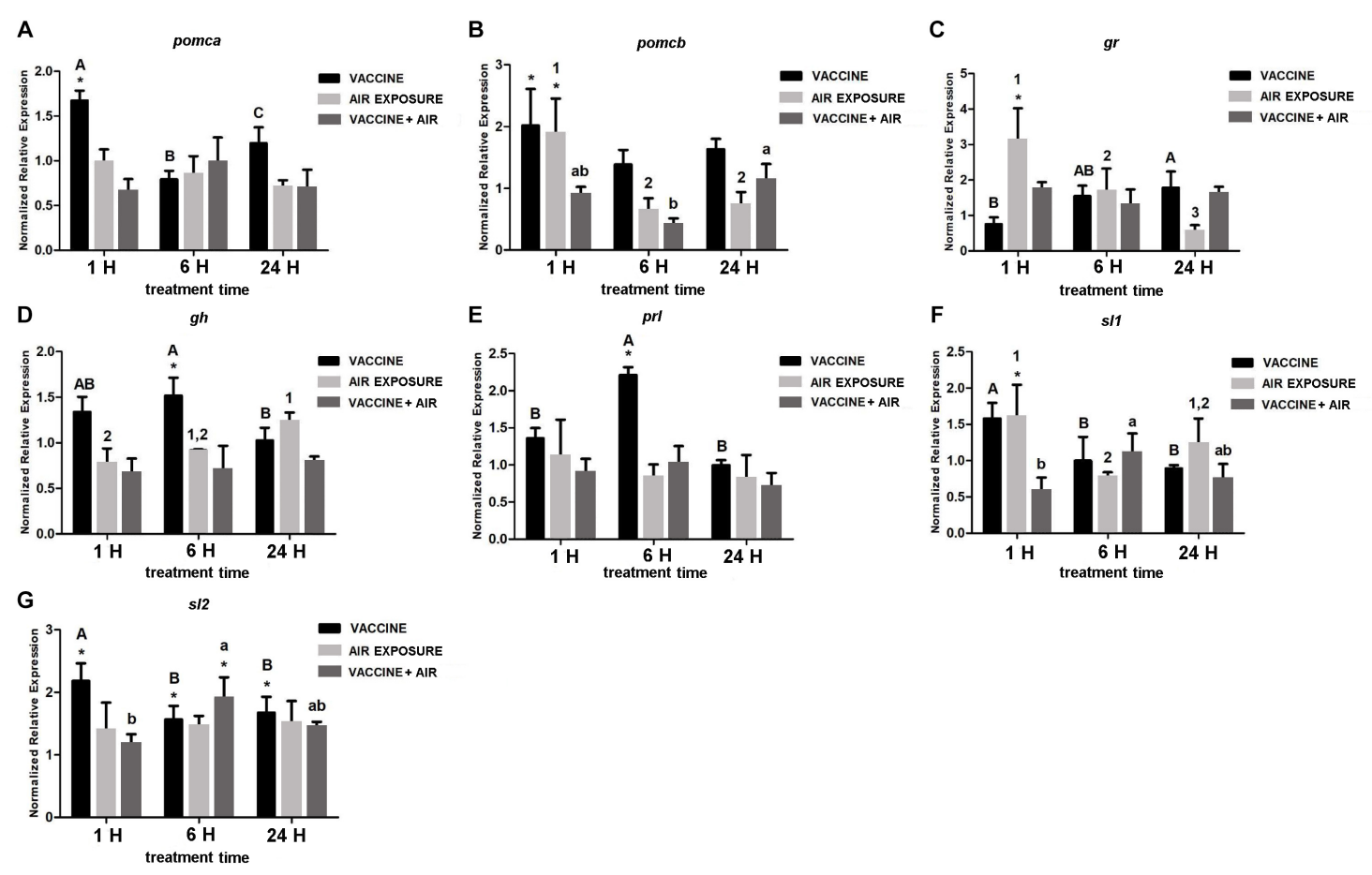

FIGURE 3 | qPCR quantification of specific mRNA accumulation in gilthead seabream (Sparus aurata L.) pituitary at 1, 6, and $24 \mathrm{~h}$ post challenge with air exposure and Vibrio anguillarum exposure. (A) pomca; (B) pomcb; (C) gr; (D) gh; (E) prl; (F) s/1; and (G) sl2 were shown as mRNA relative abundance. Data are presented as mean \pm SEM. Significant differences are indicated by capital letters in vaccine group, by numbers in air exposure group, and by lowercase letters vaccine plus air exposure. Asterisk $\left(^{*}\right)$ indicates significant difference versus control and the absence of a symbol indicates no difference $(P<0.05$; General-linear-Model test was performed for multiple comparison).
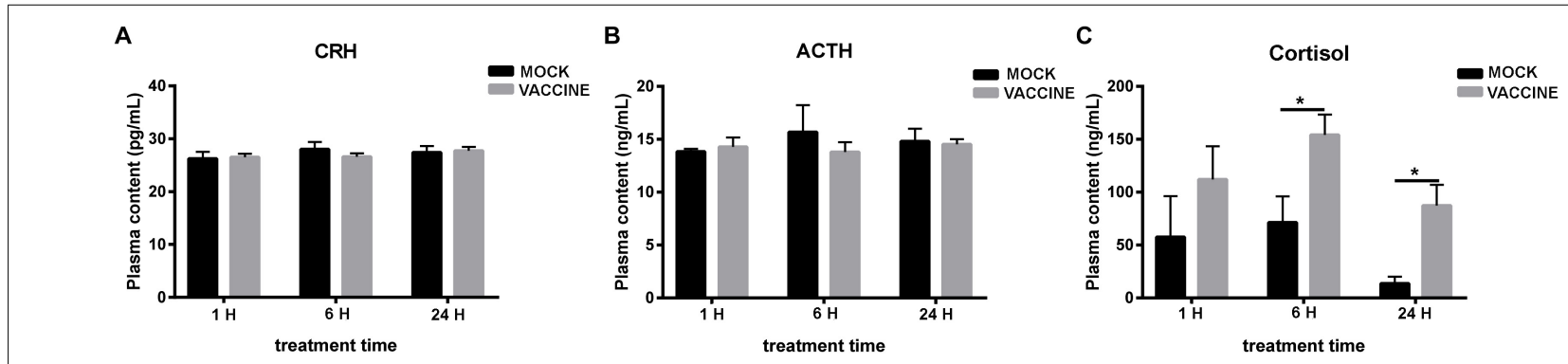

FIGURE 4 | Plasma CRH (A), ACTH (B), and cortisol (C) concentration in gilthead seabream (Sparus aurata L.) after Lactococcus bacterin or mock injection. Asterisk $(*)$ indicates significant difference between mock and vaccination groups of each time point $(P<0.05)$.

fish in which the increase was moderate (between 3 and 5 fold), though showing the same dynamics. A similar significant trend, but more moderate (over two fold increases), was observed for $h s p 70$ but not for $h s p 90$. The rest of the genes assessed, although showing some variations, did not change significantly their expression except for $g r$ in which a significant down-regulation was observed at $6 \mathrm{~h}$ (Figure 6).

\section{mRNA Expression of Immune Genes in Brain and Pituitary}

In the second experiment it was intended to determine whether an injected vaccine induced immune gene expression changes in brain and pituitary other than in stress-related genes. The results showed a very clear picture as not only some cytokines increased their expression but the level of induction was very strong. Thus, the main pro-inflammatory cytokine ill $\beta$ dramatically raised in the vaccination group at all three time points: 1,6 , and $24 \mathrm{~h}$, by 12.0, 9.36, and 7.44 fold, respectively. Similarly, cox2 was significantly upregulated by $5.25,7.77$, and 3.46 fold in the vaccination group at 1,6 , and $24 \mathrm{~h}$ post injection, respectively. The expression level of both ill $\beta$ and cox 2 peaked at $6 \mathrm{~h}$ post vaccination group. Other pro-inflammatory gene transcripts such as il6 raised significantly only 1.7 fold at $1 \mathrm{~h}$ post vaccination $(P<0.01)$, and $t n f \alpha$ was kept almost unchanged. 

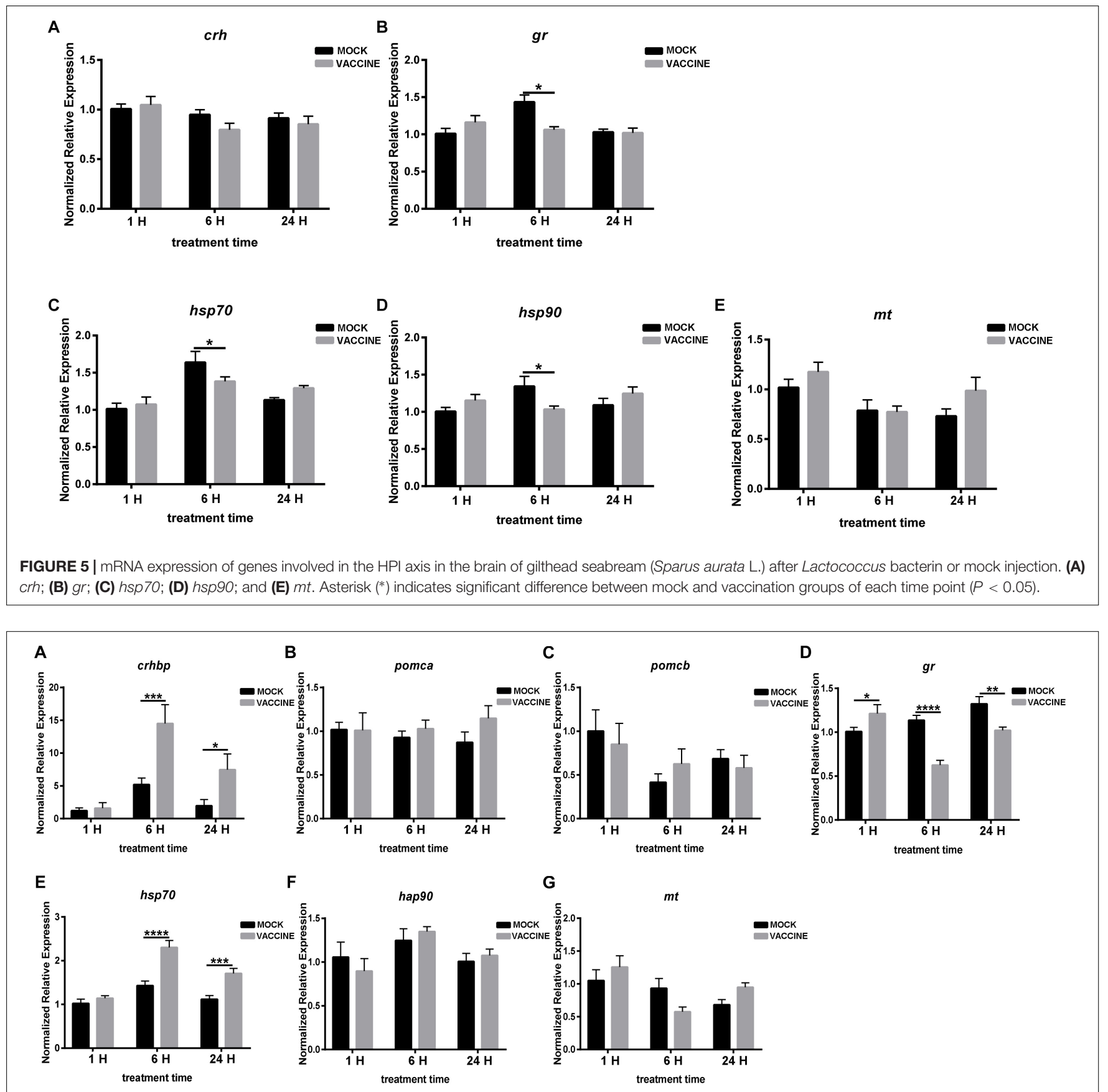

FIGURE 6 | mRNA expression of genes involved in the HPI axis in the pituitary of gilthead seabream (Sparus aurata L.) after Lactococcus bacterin or mock injection. (A) crhbp, (B) pomca, (C) pomcb; (D) gr; (E) hsp70; (F) hsp90; and (G) mt. Asterisk (*) indicates significant difference between mock and vaccination groups of each time point $(P<0.05)$.

Differently from the pro-inflammatory genes, the classical anti-inflammatory genes $\operatorname{tg} \beta \beta$ and $i l 10$ showed no significant alteration in the vaccinated groups when compared with the corresponding mock injection groups. Nevertheless, the mean values showed a non-significant but apparent increasing trend (Figure 7). The expression of lysozyme gene (lys) significantly increased in the brain of seabream at $6 \mathrm{~h}$ post vaccination, although with just 1.61 fold, and a moderate raise was also observed at $24 \mathrm{~h}$ post injection. The transcript for the complement C3 component gene (c3) showed a significant increase at $1 \mathrm{~h}$ post vaccination, by 2.35 fold; however, it decreased at 6 and $24 \mathrm{~h}$ after vaccination when compared with the corresponding mock injection groups (Figure 7). 


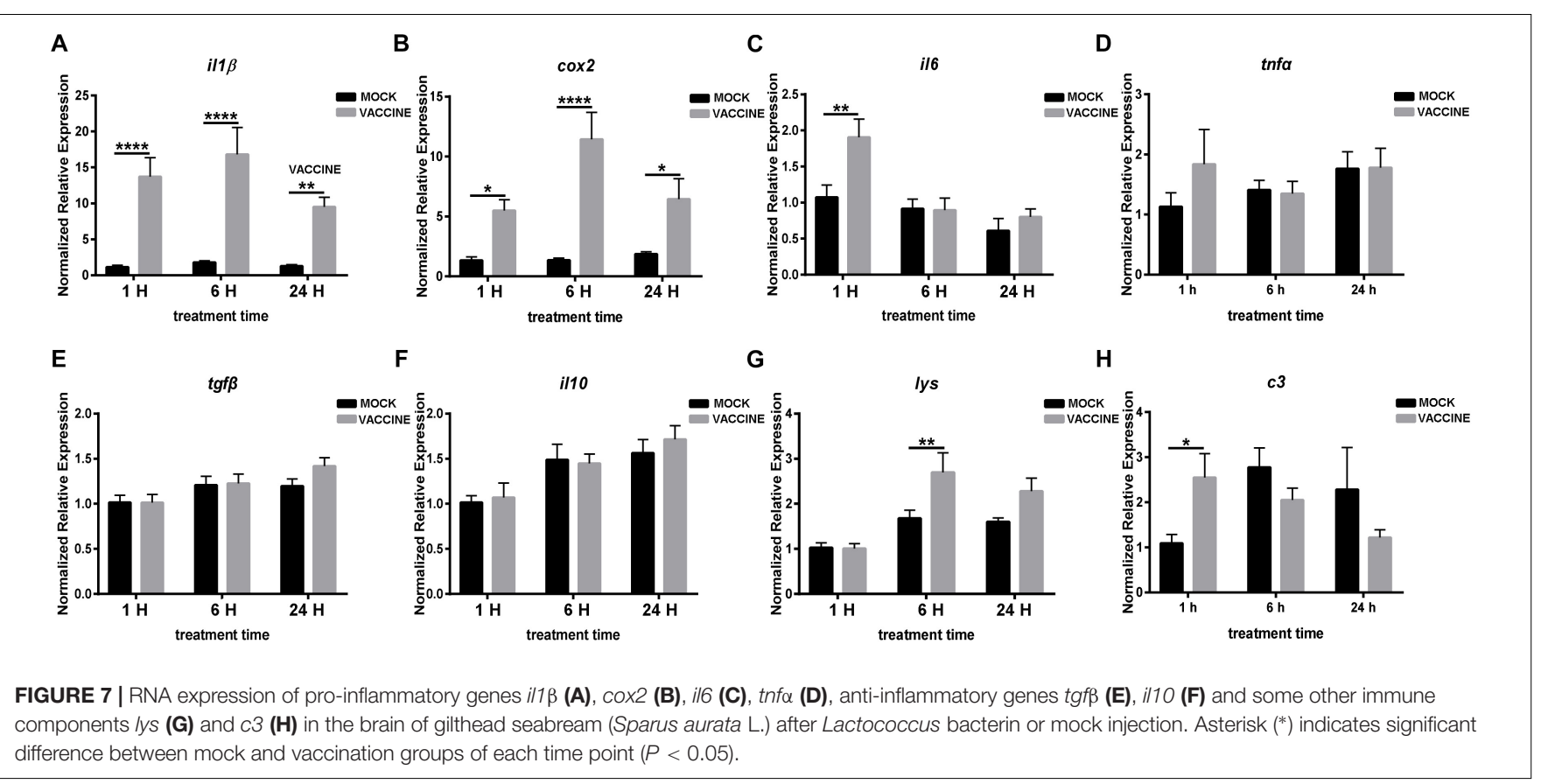

Regarding pituitary, the expression of genes related to the immune responses are shown in Figure 8. The expression of pro-inflammatory gene ill $\beta$ sharply and strongly increased at the three time points post vaccination, and it was significantly up-regulated by 20.65 and 2.94 fold at 1 and $24 \mathrm{~h}$, respectively. A similar alteration trend was observed for the expression of cox2 after vaccination, however, with less intensity. The cox2 transcript raised by 4.37, 3.16, and 2.52 fold in 1,6 , and $24 \mathrm{~h}$ vaccination groups, respectively, but significance was observed only at 1 and $6 \mathrm{~h}$ time points. The tnfa transcript was up-regulated at 1 and $6 \mathrm{~h}$ post vaccination, and the significance was only observed in the early phase of vaccination $(1 \mathrm{~h})$, by 2.74 fold. The anti-inflammatory gene $\operatorname{tg} f \beta$ showed no alteration after vaccination, and illo presented a raising trend, although significant induction was only observed at $6 \mathrm{~h}$. Compared to the mock injection, lys showed comparable levels at $1 \mathrm{~h}$ post injection, while it was distinctly up-regulated by 10.59 and 3.25 folds at 6 and $24 \mathrm{~h}$, respectively.

\section{DISCUSSION}

\section{Brain and Pituitary Stress Response to Vaccines}

The combined results from the two vaccination experiments indicate that fish perceives the vaccine as a stressor but at a limited extent. Thus, bath vaccine did not induce plasma cortisol rise, while injection vaccine did produce a differential cortisol response compared to mock injection. In addition, neither plasma CRH nor ACTH values showed important alterations after vaccine injection. Therefore, in terms of plasma hormones, it seems that fish would not perceive vaccines as primary stressors stimulating the hierarchical activation of HPI axis, although it would indirectly activate cortisol release in the case of vaccine injection linked to the air exposition period during the injection procedure. In both experiments cortisol presented an acute response dynamics, peaking at 1 or $6 \mathrm{~h}$ and recovering at $24 \mathrm{~h}$, in agreement with the studies previously reported for this species after subjecting seabream to acute stressors such as air exposure (Arends et al., 1999; Skrzynska et al., 2018). Similar increases of cortisol concentration in rainbow trout treated by vaccine injection have been previously reported as well (Funk et al., 2004; Skinner et al., 2010). However, in other works in which higher doses of bacteria were administered to Eleginops maclovinus or S. maximus, increases of cortisol lasted for 7 days or even longer after injection (Rodríguez-Quiroga et al., 2017; Oyarzún et al., 2019).

Our results also suggest that vaccines do not clearly activate the response of brain stress genes during the first hours. Thus, neither $c r h$ nor $c r h b p$ or $g r$ showed relevant modulation after bath vaccine and only slight changes were observed in $h s p$ and $g r$ after injection. Therefore, this suggests that vaccine did not activate the central stress gene response unless a physical stressor (air exposure) was included, as observed in the vaccine plus air exposure groups. This agrees with the previously reported response of $S$. aurata to different stressors (Skrzynska et al., 2018).

On the contrary, in the pituitary, vaccine did induce the gene expression of stress-related hormones like prl, gh at $6 \mathrm{~h}$ and pomca and pomcb peptides at $24 \mathrm{~h}$. Therefore, it seems that the pituitary was more sensitive than brain to immune stimulation, although at later time points (6 and $24 \mathrm{~h}$ ). This may indicate, other than a higher sensitivity, that the pituitary stimulation could be not a direct effect, but resulting from the interaction through 

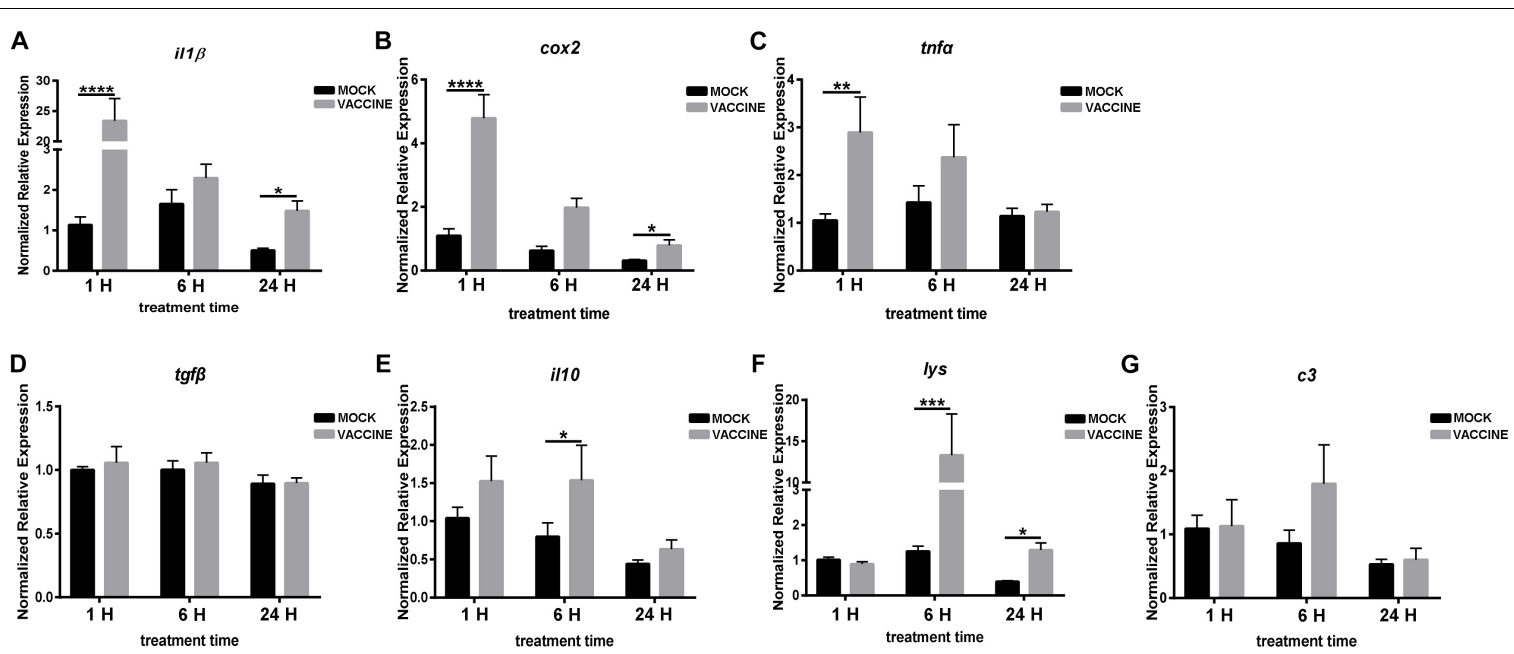

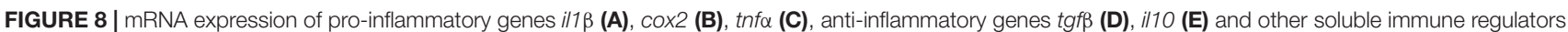
lys (F), c3 (G) in the pituitary of gilthead seabream (Sparus aurata L.) after Lactococcus bacterin or mock injection. Asterisk $\left(^{*}\right)$ indicates significant difference between mock and vaccination groups of each time point $(P<0.05)$.

biological messengers such as cytokines. This would be supported by the fact that both brain and pituitary showed a robust proinflammatory cytokine response to vaccine (see Figures 7,8 ). At this point, the research has not gone further as receptors for pomc have not yet been cloned in seabream, although attempts have been made by several laboratories. The results for trh seem to follow a similar trend than $c r h$, i.e., reduced activation of the stress axis, showing a small variation as a response to bath vaccine. At $1 \mathrm{~h}$, levels were higher than at $6 \mathrm{~h}$ which matches with previous results of Ruiz-Jarabo et al. (2017) and Skrzynska et al. (2018). This response could also be related to an inhibition of the thyroid hormone axis modulating energetic responses, thus contributing to save energy resources. This moderate response is also linked to the expression of both pomc genes. Thus, pomcb showed a decrease of its expression at $6 \mathrm{~h}$ as trh, whereas pomca and $c r h$ maintained unaltered levels.

It is worth to note that vaccination caused a raise of cortisol together with some alteration of both $h s p$ and $m t$ in brain and pituitary. Metallothioneins, similarly than HSP are involved in stress response, and their expression can be induced by cortisol in fish (Hyllner et al., 1989) as a result of both abiotic and biotic stressors (Iwama et al., 1999; Roberts et al., 2010; Yamashita et al., 2010). In addition, our recent data in skin mucus showed both an increment of cortisol induced by $V$. anguillarum vaccine and also a significant rise of hsp70 (Khansari et al., 2018). During stress, global RNA translation is supposed to be reduced to save energy, while a selective translation is up-regulated, which facilitates coping with challenges (Holcik and Sonenberg, 2005; Tort and Teles, 2011). Thus, after vaccination, a decreased expression of some stress genes together with the enhancement of other key response genes might be associated to energy savings, and thus protective immunity responses could be maintained (Pulendran and Ahmed, 2011).
Besides the role of GR in mediating the glucocorticoid effect of cortisol in target tissues, some other factors such as CRH and CRHBP could serve as potential feedback agents in the HPI axis. CRH is an ancient stress neuropeptide which is essential for facilitating the adaptive response to environmental stressors (Denver, 1999). Binding of CRH with its receptors in pituitary cells stimulates ACTH production. With a high affinity to CRH, CRHBP can sequester CRH in the circulation and thus modulate its bioavailability (Huising et al., 2004). Normally, a large proportion of total circulating $\mathrm{CRH}$ is complexed with CRHBP, and therefore the availability for receptor activation is low (Behan et al., 1997). Thus, CRHBP would act as another potential negative feedback agent of HPI axis as suggested by the up-regulation of crhbp in the pituitary of seabream after vaccination. This agrees with such a proposed role of CRHBP during acute stress in $S$. aurata in previous works (Martos-Sitcha et al., 2014).

Combining the results of $g r$ expression and crhbp with the plasma cortisol content, we could speculate that after cortisol increase, up-regulation of crhbp and down-regulation of $g r$ constitute two feedback factors of HPI axis. They would indirectly inhibit the bioavailability of circulating CRH and then suppress the new production of cortisol, reducing the binding of cortisol with GR and finally leading to the descent bioactivity of cortisol. Besides, induction of inflammation may help to eliminate potential invading pathogens and dead cells. On the other hand, prolonged hyperactivation of the immune response may be detrimental and therefore anti-inflammatory cytokines would help to regulate this activation process, which matches with the increase of il10 observed both in brain and pituitary. Thus, the simultaneous alteration of plasma cortisol, decreased expression of $g r$, up-regulated expression of crhbp and pro-inflammatory genes, and the down-regulation of anti-inflammatory genes 
could constitute a beneficial picture for homeostasis and recovery of fish.

Overall, in terms of the effect of the vaccine (route of vaccination or the bacterial species) the comparison between both experiments indicates that the stress response to vaccines focuses more in pituitary or head kidney (associated to the increase of cortisol) than in the brain. As mentioned before, while slight changes are recorded in either plasma hormones or genes in brain, in pituitary bath vaccine did modify pomca, pomcb expression at $1 \mathrm{~h}$ and pomcb at $6 \mathrm{~h}$. In addition, $g r$ increases at $6 \mathrm{~h}$ after bath and decreases after injection vaccination.

\section{Immune Gene Response in Brain and Pituitary After Vaccine Injection}

Immune responses in fish such as inflammatory and antibody response elicited by bacteria or pathogen-associated molecular patterns (PAMPs) including LPS, poly (I:C), can be detected notably in immune organs like spleen and head kidney (Cvitanich et al., 1991; Reyes-Cerpa et al., 2012; Martínez et al., 2018; Sheng et al., 2019). A relevant result of the present study is the strong immune response occurring both in brain and pituitary after vaccination regardless the overall stress response. Thus, very significant alterations of $i l 1 \beta, \operatorname{cox} 2, l y s$, and $c 3$ were observed in the brain and pituitary of vaccinated seabream. IL1 $\beta$ is one of the first cytokines produced at the inflammation site that contributes to induce the expression of other cytokines including TNF $\alpha$, IL1 $\alpha$, IL6, IL8, COX2, MCP1 (Weber et al., 2010; Zou and Secombes, 2016). Cox2 is a potent mediator of inflammation encoding a prostaglandin-endoperoxide synthase 2 , which is a rate limiting enzyme for formation of prostaglandins (PG) functioning under a wide variety of challenging conditions (Smith et al., 1996; Ricciotti and FitzGerald, 2011). The significant raise of pro-inflammatory signaling genes observed in brain and pituitary suggests that vaccines induced inflammation in these two tissues. It can also be speculated that stimulation of cortisol by the vaccine may be associated with an interaction of ill $\beta$ expression at the pituitary, as previously proposed (see Tort and Teles, 2011). Moreover, the increased expression of $c 3$, responsible for the complement protein $\mathrm{C} 3$, and even more the dramatic raise of $l y s$, responsible for the bacteriolytic protein lysozyme (Sunyer et al., 1997; Hernández and Tort, 2003; Saurabh and Sahoo, 2008), indicates an effective activation of innate immune responses in the central neuroendocrine tissues after the intraperitoneal vaccination. The combination of the alteration of inflammatory genes plus the increase of the immune innate genes supports the occurrence of a significant immune response in the pituitary.

There is not precisely known what are the precise mechanisms of interaction between hormone elements and immune agents. Normally, due to the protection of the blood brain barrier, pathogens can hardly access to the brain or pituitary. However, some mediators such as cytokines can play a role of connecting antigens and response (Banks et al., 1995). In our previous works we observed that both the medium from the in vitro cultured spleen and recombinant IL1 $\beta$ presented a significant effect on the in vitro immune response of trout pituitary (Liu et al., 2019). Thus, the immune response in the central neuroendocrine system might be regulated by some mediators produced and released into the bloodstream by lymphoid organs as a response to the bacterin delivered by intraperitoneal injection. Further studies will be necessary to precise the mechanisms that can confirm this hypothesis.

Although both brain and pituitary present a robust immune reaction, it is worth noting that the expression trends of immune genes are different between these organs, and this may be related to the respective tissue architecture. Brain is constituted by neurons and also glia which account for an abundant portion of the brain cell population, acting as the primary resident macrophages to elicit both innate and adaptive immune responses (Yang et al., 2010; Schwartz et al., 2013; Lenz and Nelson, 2018). Thus, while pituitary have endocrine cells as the predominant population, just some stellate cells are hypothetically the functional immune cells (Glennon et al., 2015). In brain, the participation of glial cells in immune response could be quantitatively rather higher. Therefore, we can hypothesize that alterations in the transcription levels of immune genes in response to intraperitoneal vaccine injection might result from the different architecture and cell composition of these two organs, thus leading to different signaling elements involved in the immune response. In the case of L. garvieae, it is also possible that the strong induction of the pro-inflammatory response could be associated to the pathogenic neurodegenerative effect of the L. garvieae that has been shown to produce brain damage in fish (Vendrell et al., 2006). Moreover, although these hypotheses need further investigation, our findings support the fact that fish brain is capable of inducing a strong inflammatory response.

\section{CONCLUSION}

Vaccination, either via bath or injection did not involve a significant induction of brain-pituitary stress response, although cortisol showed a moderate increase. Other than assuming that such antigen stimulus does not involve a direct and high central perception response, the observed reaction could be also associated to the altered feedback genes of the HPI axis $g r$ and crhbp that may have played a relevant role in preventing the maintenance of higher cortisol levels in brain and pituitary and therefore also preventing cortisol immunosuppressive consequences. Such a mechanism could modulate the initial stress response and the pleiotropic cortisol action, thus helping to prevent the putative suppression of an active immune response in the neuroendocrine centers. Thus, the raise of cortisol caused by the vaccination would not be achieved through the initial activation of the central brainpituitary axis elements. Besides, a robust immune response was elicited both in brain and pituitary regardless the route of administration, bath or injection, as shown by the up-regulation of cytokines and innate response genes. Thus, results suggest an active and direct immune action of the vaccine components in brain and pituitary tissues uncoupled from the initial stress HPI axis response. 


\section{DATA AVAILABILITY}

All datasets for this study are included in the manuscript and the supplementary files.

\section{ETHICS STATEMENT}

All experimental procedures were submitted by the Ethical Committee of the Universitat Autonoma de Barcelona (CEEAH), in accordance with the international European Guiding Principles for Biomedical Research Involving Animals (EU2010/63) and authorized by the regional authority (Generalitat de Catalunya Procedure Ref. 10208).

\section{AUTHOR CONTRIBUTIONS}

LT, JM, and FR-L conceived and designed the experiments. $\mathrm{XL}, \mathrm{AK}, \mathrm{MT}$, and FR-L performed the experiments. XL, AK, GM-R, LT, and FR-L analyzed the data. YZ, GM-R, JM, and FR-L contributed the reagents and materials. XL, AK, MT, YZ, JM, GM-R, FR-L, and LT contributed to the writing of

\section{REFERENCES}

Arends, R. J., Mancera, J. M., Muñoz, J. L., Wendelaar Bonga, S. E., and Flik, G. (1999). The stress response of the gilthead sea bream (Sparus aurata L.) to air exposure and confinement. J. Endocrinol. 163, 149-157. doi: 10.1677/joe. 0.1630149

Banks, W. A., Kastin, A. J., and Broadwell, R. D. (1995). Passage of cytokines across the blood-brain barrier. Neuroimmunomodulation 2, 241-248. doi: 10.1159/ 000097202

Behan, D. P., Khongsaly, O., Owens, M. J., Chung, H. D., Nemeroff, C. B., and De Souza, E. B. (1997). Corticotropin-releasing factor (CRF), CRF-binding protein (CRF-BP), and CRF/CRF-BP complex in Alzheimer's disease and control postmortem human brain. J. Neurochem. 68, 2053-2060. doi: 10.1007/ BF03347284

Cerdá-Reverter, J. M., and Canosa, L. F. (2009). "Neuroendocrine systems of the fish brain," in Fish Neuroendocrinology, Vol. 28, eds N. J. Bernier, G. Van Der Kraak, A. P. Farrell, and C. J. Brauner (Cambridge, MA: Academic Press), 3-74. doi: 10.1016/s1546-5098(09)28001-0

Cvitanich, J. D., Garaten, O., and Smith, C. E. (1991). The isolation of a rickettsialike organism causing disease and mortality in chilean salmonids and its confirmation by koch's postulate. J. Fish Dis. 14, 121-145. doi: 10.1111/j.13652761.1991.tb00584.x

Denver, R. J. (1999). Evolution of the corticotropin-releasing hormone signaling system and its role in stress-induced phenotypic plasticity. Ann. N. Y. Acad. Sci. 897, 46-53. doi: 10.1111/j.1749-6632.1999.tb07 877.x

Figueras, A., Santarem, M. M., and Novoa, B. (1998). Influence of the sequence of administration of beta-glucans and a vibrio damsela vaccine on the immune response of turbot (Scophthalmus maximus L.). Vet. Immunol. Immunopathol. 64, 59-68. doi: 10.1016/s0165-2427(98)00114-7

Flik, G., Peter, H. M., Klaren, P. H. M., Erwin, H., Van den Burg, J. R., and Huising, M. O. (2006). CRF and stress in fish. Gen. Comp. Endocrinol. 146, 36-44. doi: 10.1016/j.ygcen.2005.11.005

Frans, I., Michels, C. W., Bossier, P., Willems, K. A., Lievens, B., and Rieders, H. (2011). Vibrio anguillarum as a fish pathogen: virulence factors, diagnosis and prevention. J. Fish Dis. 34, 643-666. doi: 10.1111/j.1365-2761.2011.01 279.x

Funk, V. A., Jones, S. R., Kim, E., Kreiberg, H., Taylor, K., Wu, S., et al. (2004). The effect of vaccination and sea water entry on immunocompetence and the manuscript. All authors read, corrected and approved the final manuscripts.

\section{FUNDING}

This research was funded by projects AGL2016-76069C2 and AGL2016-81808-REDT of MICINN (Spain) with the support of FEDER funds (European Union). $\mathrm{XL}$ was recipient of grants named Major program of science and technology commission foundation of Chongqing (cstc2014yykfc80001), and Doctoral Fund of Southwest University (SWU119006). AK was recipient of a grant from the Iran Ministry of Science, Research and Technology. LT and FR-L are members of the Xarxa d'Aquicultura de Catalunya.

\section{ACKNOWLEDGMENTS}

Thanks are given to Irene Brandts and Aleix Castellvi for their assistance in the sample collection.

susceptibility to kudoa thyrsites in Atlantic salmon (Salmo salar L.). Fish Shellfish Immunol. 17, 375-387. doi: 10.1016/j.fsi.2004.04.014

Glennon, E., Kaunzner, U. W., Gagnidze, K., McEwen, B. S., and Bulloch, K. (2015). Pituitary dendritic cells communicate immune pathogenic signals. Brain Behav. Immun. 50, 232-240. doi: 10.1016/j.bbi.2015.07.007

Gorissen, M., and Flik, G. (2016). "The endocrinology of the stress response in fish: an adaptation-physiological view," in Biology of Stress in Fish, eds C. Schreck, L. Tort, A. P. Farrell, and C. B. Brauner (Cambridge, MA: Academic Press), 75-111. doi: 10.1016/b978-0-12-802728-8.00003-5

Hastein, T., Gudding, R., and Evensen, O. (2005). Bacterial vaccines for fish-an update of the current situation worldwide. Dev. Biol. 121, 55-74.

Hernández, A., and Tort, L. (2003). Annual variation of complement, lysozyme and agglutination in serum of the gilthead seabram Sparus aurata. Fish Shellfish Immunol. 15, 479-481. doi: 10.1016/s1050-4648(03)00024- $\mathrm{x}$

Holcik, M., and Sonenberg, N. (2005). Translational control in stress and apoptosis. Nat. Rev. Mol. Cell Biol. 6, 318-327. doi: 10.1038/nrm1618

Huising, M. O., Metz, J. R., van Schooten, C., Taverne-Thiele, A. J., Hermsen, T., Verburg-van Kemenade, B. M. L., et al. (2004). Structural characterisation of a cyprinid (Cyprinus carpio L.) CRH, CRH-BP and CRH-R1, and the role of these proteins in the acute stress response. J. Mol. Endocrinol. 32, 627-648. doi: $10.1677 /$ jme.0.0320627

Hyllner, S. J., Andersson, T., Haux, C., and Olsson, P. E. (1989). Cortisol induction of metallothionein in primary culture of rainbow trout hepatocytes. J. Cell Physiol. 139, 24-28. doi: 10.1002/jcp.1041390105

Iwama, G. K., Vijayan, M. M., Forsyth, R. B., and Ackerman, P. A. (1999). Heat shock proteins and physiological stress in fish. Am. Zool. 39, 901-909. doi: $10.2307 / 3884400$

Kaattari, S. L., and Tripp, R. A. (1987). Cellular mechanisms of glucocorticoid immunosuppression in salmon. J. Fish Biol. 31, 129-132. doi: 10.1111/j.10958649.1987.tb05304.x

Karalis, K., Louis, J. M., Bae, D., Hilderbrand, H., and Majzoub, J. A. (1997). CRH and the immune system. J. Neuroimmunol. 72, 131-136. doi: 10.1016/s01655728(96)00178-6

Khansari, A. R., Balasch, J. C., Vallejos-Vidal, E., Parra, D., Reyes-Lopez, F. E., and Tort, L. (2018). Comparative immune- and stress-related transcript response induced by air exposure and Vibrio anguillarum bacterin in rainbow trout (Oncorhynchus mykiss) and Gilthead seabream (Sparus aurata) mucosal surfaces. Front. Immunol. 9:856. doi: 10.3389/fimmu.2018. 00856 
Khansari, A. R., Parra, D., Reyes-Lopez, F. E., and Tort, L. (2017). Modulatory in vitro effect of stress hormones on the cytokine response of rainbow trout and gilthead seabream head kidney stimulated with Vibrio anguillarum bacterin. Fish Shellfish Immun. 70, 736-749. doi: 10.1016/j.fsi.2017. 09.009

Kudielka, B. M., and Kirschbaum, C. (2007). "Biological bases of the stress response," in Stress and Addiction: Biological and Psychological Mechanisms, ed. M. E. Al'Absi (San Diego, CA: Academic Press), 3-19. doi: 10.1016/b978012370632-4/50004-8

Lamers, C. H. J., Dehaas, M. J. H., and Vanmuiswinkel, W. B. (1985). The reaction of the immune system of fish to vaccination - development of immunological memory in carp, Cyprinus carpio L, following direct immersion in Aeromonas hydrophila bacterin. J. Fish Dis. 8, 253-262. doi: 10.1111/j.1365-2761.1985. tb00941.x

Lenz, K. M., and Nelson, L. H. (2018). Microglia and beyond: innate immune cells as regulators of brain development and behavioral function. Front. Immunol. 9:698. doi: 10.3389/fimmu.2018. 00698

Liu, X., Khansari, A. R., and Tort, L. (2019). Fish pituitary show an active immune response after in vitro stimulation with vibrio bacterin. Gen. Comp. Endocrinol. 275, 65-72. doi: 10.1016/j.ygcen.2019. 02.011

Martínez, D., Vargas-Lagos, C., Oyarzún, R., Loncoman, C. A., Pontigo, J. P., Yáñez, A. J., et al. (2018). Temperature modulates the immunological response of the sub-antarctic notothenioid fish Eleginops maclovinus injected with Piscirickettsia salmonis. Fish Shellfish Immunol. 82, 492-503. doi: 10.1016/j.fsi. 2018.08.042

Martos-Sitcha, J. A., Wunderink, Y. S., Straatjes, J., Skrzynska, A. K., Mancera, J. M., and Martínez-Rodríguez, G. (2014). Different stressors induce differential responses of the CRH-stress system in the gilthead sea bream (Sparus aurata). Comp. Biochem. Physiol. A Mol. Integr. Physiol. 177, 49-61. doi: 10.1016/j.cbpa. 2014.07.021

Metz, J. R., Huising, M. O., Leon, K., Verburg-van Kemenade, B. M. L., and Flik, G. (2006). Central and peripheral interleukin-1 beta and interleukin1 receptor I expression and their role in the acute stress response of common carp Cyprinus carpio L. J. Endocrinol. 191, 25-35. doi: 10.1677/joe.1.0 6640

Mutoloki, S., Munang'andu, H. M., and Evensen, O. (2015). Oral vaccination of fish - antigen preparations, uptake, and immune induction. Front. Immunol. 6:519. doi: 10.3389/fimmu.2015.00519

Ottaviani, E., Franchini, A., and Franceschi, C. (1995). Evidence for the presence of immunoreactive pomc-derived peptides and cytokines in the thymus of the goldfish (Carassius auratus). Histochem. J. 27, 597-601. doi: 10.1007/ bf00173096

Oyarzún, R., Vargas-Lagos, C., Martínez, D., Muñoz, J. L. P., Dantagnan, L. P., and Vargas-Chacoff, L. (2019). The effects of intraperitoneal administration of Francisella noatunensis subsp. noatunensis on hepatic intermediary metabolism and indicators of stress in Patagonian blennie Eleginops maclovinus. Comp. Biochem. Physiol. B Biochem. Mol. Biol. 230, 48-56. doi: 10.1016/j.cbpb. 2019.01.013

Padgett, D. A., and Glaser, R. (2003). How stress influences the immune response. Trends Immunol. 24, 444-448. doi: 10.1016/S1471-4906(03)00 $173-\mathrm{X}$

Pfaffl, M. W. (2001). A new mathematical model for relative quantification in real-time RT-PCR. Nucleic Acids Res. 29:e45. doi: 10.1093/nar/29.9.e45

Plant, K. P., and LaPatra, S. E. (2011). Advances in fish vaccine delivery. Dev. Comp. Immunol. 35, 1256-1262. doi: 10.1016/j.dci.2011.03.007

Pulendran, B., and Ahmed, R. (2011). Immunological mechanisms of vaccination. Nat. Immunol. 12, 509-517. doi: 10.1038/ni.2039

Quintanar, J. L., and Guzman-Soto, I. (2013). Hypothalamic neurohormones and immune responses. Front. Integr. Neurosci. 7:56. doi: 10.3389/fnint.2013. 00056

Reyes-Cerpa, S., Reyes-López, F. E., Toro-Ascuy, D., Ibañez, J., Maisey, K., Sandino, A. M., et al. (2012). IPNV modulation of pro and anti-inflammatory cytokine expression in Atlantic salmon might help the establishment of infection and persistence. Fish Shellfish Immunol. 32, 291-300. doi: 10.1016/j.fsi.2011. 11.018
Ricciotti, E., and FitzGerald, G. A. (2011). Prostaglandins and inflammation. Arterioscler. Thromb. Vasc. Biol. 31, 986-1000. doi: 10.1161/ATVBAHA.110. 207449

Roberts, R. J., Agius, C., Saliba, C., Bossier, P., and Sung, Y. Y. (2010). Heat shock proteins (chaperones) in fish and shellfish and their potential role in relation to fish health: a review. J. Fish Dis. 33, 789-801. doi: 10.1111/j.1365-2761.2010. 01183.x

Rodgers, C. J. (1990). Immersion vaccination for control of fish furunculosis. Dis. Aquat. Organ. 8, 69-72. doi: 10.3354/dao00 8069

Rodríguez-Quiroga, J. J., Otero-Rodiño, C., Suárez, P., Nieto, T. P., García Estévez, J. M., San Juan, F., et al. (2017). Differential effects of exposure to parasites and bacteria on stress response in turbot Scophthalmus maximus simultaneously stressed by low water depth. J. Fish Biol. 91, 242-259. doi: 10.1111/jfb.1 3338

Rotllant, J., Ruane, N. M., Dinis, M. T., Canarion, A. V. M., and Power, D. M. (2006). Intra-adrenal interactions in fish: catecholamine stimulated cortisol release in sea bass (Dicentrarchus labrax L.). Comp. Biochem. Physiol. A. 143, 375-381. doi: 10.1016/j.cbpa.2005.12.027

Ruiz-Jarabo, I., Klaren, P. H. M., Louro, B., Martos-Sitcha, J. A., Pinto, P. I. S., Vargas-Chacoff, L., et al. (2017). Characterization of the peripheral thyroid system of gilthead seabream acclimated to different ambient salinities. Comp. Biochem. Physiol. A Mol. Integr. Physiol. 203, 24-31. doi: 10.1016/j.cbpa.2016. 08.013

Sapolsky, R. M., Romero, L. M., and Munck, A. U. (2000). How do glucocorticoids influence stress responses? Integrating permissive, suppressive, stimulatory, and preparative actions. Endocr. Rev. 21, 55-89. doi: 10.1210/er. 21.1.55

Saurabh, S., and Sahoo, P. K. (2008). Lysozyme: an important defence molecule of fish innate immune system. Aquac. Res. 39, 223-239. doi: 10.1111/j.1365-2109. 2007.01883.x

Schreck, C. B., and Tort, L. (2016). "The concept of stress in fish," in Biology of Stress in Fish. Fish Physiology Series, Vol. 35, eds C. B. Schreck, L. Tort, A. T. Farrell, and C. J. Brauner (Cambridge, MA: Academic Press), $2-34$.

Schwartz, M., Kipnis, J., Rivest, S., and Prat, A. (2013). How do immune cells support and shape the brain in health, disease, and aging? J. Neurosci. 33, 17587-17596. doi: 10.1523/Jneurosci.3241-13. 2013

Sheng, X. Z., Chai, B. H., Wang, Z. F., Tang, X. Q., Xiang, J., and Zhan, W. B. (2019). Polymeric immunoglobulin receptor and mucosal IgM responses elicited by immersion and injection vaccination with inactivated Vibrio anguillarum in flounder (Paralichthys olivaceus). Aquaculture 505, 1-11. doi: 10.1016/j. aquaculture.2019.02.045

Skinner, L. A., LaPatra, S. E., Adams, A., Thompson, K. D., Balfry, S. K., McKinley, R. S., et al. (2010). Supra-physiological levels of cortisol suppress lysozyme but not the antibody response in Atlantic salmon, Salmo salar L., following vaccine injection. Aquaculture 300, 223-230. doi: 10.1016/j.aquaculture.2010. 01.002

Skrzynska, A. K., Maiorano, E., Bastaroli, M., Naderi, F., Míguez, J. M., MartínezRodríguez, G., et al. (2018). Impact of air exposure on vasotocinergic and isotocinergic systems in gilthead sea bream (Sparus aurata): new insights on fish stress response. Front. Physiol. 9:96. doi: 10.3389/fphys.2018.0 0096

Smith, W. L., Garavito, R. M., and DeWitt, D. L. (1996). Prostaglandin endoperoxide $\mathrm{H}$ synthases (cyclooxygenases)-1 and -2. J. Biol. Chem. 271, 33157-33160. doi: 10.1074/jbc.271.52.33157

Sunyer, J. O., Tort, L., and Lambris, J. D. (1997). Strutural C3 diversity in fish: characterization of five forms of C3 in the diploid fish Sparus aurata. J. Immunol. 158, 2813-2821.

Teles, M., Boltaña, S., Reyes-López, F., Santos, M. A., Mackenzie, S., and Tort, L. (2013). Effects of chronic cortisol administration on global expression of GR and the liver transcriptome in Sparus aurata. Mar. Biotechnol. 15, 104-114. doi: 10.1007/s10126-012-9467-y

Tort, L. (2011). Stress and immune modulation in fish. Develop. Comp. Immunol. 35, 1366-1375. doi: 10.1016/j.dci.2011. 
Tort, L., and Teles, M. (2011). "The endocrine response to stress - a comparative view," in Basic and Clinical Endocrinology Up-To-Date, ed. A. Fulya (London: InTech Press), 263-286.

Vendrell, D., Balcázar, J. L., Ruiz-Zarzuela, I., de Blas, I., Gironés, O., and Múzquiz, J. L. (2006). Lactococcus garvieae in fish: a review. Comp. Immunol. Microbiol. Infect. Dis. 29, 177-198. doi: 10.1016/j.cimid.2006. 06.003

Weber, A., Wasiliew, P., and Kracht, M. (2010). Interleukin-1 (IL-1) pathway. Sci. Signal. 3:cm1. doi: 10.1126/scisignal.3105 $\mathrm{cm} 1$

Yamashita, M., Yabu, T., and Ojima, N. (2010). Stress protein hsp70 in fish. Aqua Biosci. Monogr. 3, 111-141. doi: 10.5047/absm.2010.00304.0111

Yang, I., Han, S. J., Kaur, G., Crane, C., and Parsa, A. T. (2010). The role of microglia in central nervous system immunity and glioma immunology. J. Clin. Neurosci. 17, 6-10. doi: 10.1016/j.jocn.2009.05.006
Zou, J., and Secombes, C. J. (2016). The function of fish cytokines. Biology 5:23. doi: 10.3390/biology5020023

Conflict of Interest Statement: The authors declare that the research was conducted in the absence of any commercial or financial relationships that could be construed as a potential conflict of interest.

Copyright (c) 2019 Liu, Khansari, Teles, Martínez-Rodríguez, Zhang, Mancera, Reyes-López and Tort. This is an open-access article distributed under the terms of the Creative Commons Attribution License (CC BY). The use, distribution or reproduction in other forums is permitted, provided the original author(s) and the copyright owner(s) are credited and that the original publication in this journal is cited, in accordance with accepted academic practice. No use, distribution or reproduction is permitted which does not comply with these terms. 